\title{
Divergência genética entre tipos especiais de arroz a partir de técnicas multivariadas
}

\author{
Genetic divergence among special rice types trought of multivariate techniques
}

\author{
Rafael Hydalgo Passeri-lima', Luiz Beja Moreira ${ }^{2}$, Higino Marcos Lopes ${ }^{2}$, Maurício Ballesteiro \\ Pereira $^{2}$, Bruna Rafaela da Silva Menezes ${ }^{2 \star}$, Diogo de Vilela Marinho ${ }^{2}$ \\ ${ }^{1}$ Universidade Federal Rural do Rio de Janeiro, Campos dos Goytacazes, RJ, Brasil. \\ ${ }^{2}$ Universidade Federal Rural do Rio de Janeiro, Seropédica, RJ, Brasil. *Autor para correspondência: brunarafamenezes@hotmail.com
}

Submissão: 22/04/2019 / Aceite: 22/06/2020

\begin{abstract}
RESUMO
O mercado brasileiro de arroz prioriza o consumo de arroz branco polido. Entretanto, existem demandas por tipos especiais. A estimativa da divergência genética é importante para o melhoramento genético, pois permite a seleção de genitores em sistemas de cruzamentos controlados. Assim, os objetivos deste trabalho foram indicar a contribuição relativa dos caracteres avaliados para a dissimilaridade genética e avaliar a divergência genética entre genótipos de tipos especiais de arroz por dois métodos diferentes de agrupamento. O experimento foi conduzido no ano de outubro de 2012 a março de 2013, na UFRRJ, Seropédica, RJ. O delineamento utilizado foi em blocos ao acaso, com cinco repetições. Os tratamentos constaram dos genótipos Caiapó, Vermelho Pequeno, IAC 300, IAC 400 e IAC 500. A medida de dissimilaridade adotada foi a distância euclidiana. Foram utilizados dois métodos diferentes de otimização: o método de otimização de Tocher e o método hierárquico UPGMA (Unweighted Pair-Group Method using Arithmetic Avarages). Os genótipos Caiapó e Vermelho Pequeno estiveram em diferentes grupos heteróticos em relação aos genótipos IAC 300 e IAC 400, independentemente do método de agrupamento utilizado. Verificou-se que a característica produtividade foi a que mais influenciou na variação total.
\end{abstract}

PALAVRAS-CHAVE: arroz vermelho, produtividade, variabilidade genética.

\begin{abstract}
The brazilian rice market prioritizes the consumption of polished white rice. However, there are demands for special types. The estimation of genetic divergence is important for genetic improvement, as it allows the selection of parents in controlled crossbreeding systems. Thus, the objectives of this work were to indicate the relative contribution of the evaluated traits to the genetic dissimilarity and to evaluate the genetic divergence among genotypes of special types of rice by two different methods of grouping. The experiment was carried out from October 2012 to March 2013, at the UFRRJ, Seropédica, RJ. The design used was in randomized blocks, with five replications. The treatments consisted of the genotypes Caiapó, Vermelho Pequeno, IAC 300, IAC 400 and IAC 500. The measure of dissimilarity adopted was the Euclidean distance. Two different optimization methods were used: the Tocher optimization method and the UPGMA (Unweighted Pair-Group Method using Arithmetic Averages) hierarchical method. The genotypes Caiapó and Vermelho Pequeno were in different heterotic groups in relation to the genotypes IAC 300 and IAC 400, using the clustering method used. It was found that the yield trait was the one that most influenced the total variation.
\end{abstract}

KEYWORDS: red rice, yield, genetic variability.

\section{INTRODUÇÃO}

Os tipos especiais de arroz, como o vermelho, o preto, glutinoso, aromático e o arbório, possuem maior valor agregado em comparação ao arroz branco. $O$ arroz vermelho e o preto possuem alta concentração de antioxidantes, responsáveis pela redução de radicais livres (ANGGRAINI et al. 2015). Plantas de arroz vermelho e o preto são consideradas invasoras em campos de cultivo de arroz branco devido ao seu porte elevado e dormência nas sementes dentre outras características indesejáveis. Porém, 
existem genótipos de arroz vermelho com características semelhantes aos de arroz branco, como período curto de dormência de sementes pós-colheita (MENEZES et al. 2013).

$O$ melhorista genético necessita de genes que confiram características de interesse às suas pesquisas. Para isso, o melhorista tem como instrumento as "coleções de trabalho" (NASS et al. 1992). Estas possuem acessos com características específicas de um programa de melhoramento. Um Banco Ativo de Germoplasma (BAG) caracteriza-se por manter um número maior de acessos e que seja representativo da variabilidade genética da espécie ou gênero (VEIGA et al. 2012). Com isso, evita-se o estreitamento da base genética com a perda ou diminuição da variabilidade genética de espécies cultivadas, parentes silvestres e variedades locais (HALLAUER \& MIRANDA 1988).

A estatística multivariada corresponde a técnicas que utilizam todas as informações de características para a interpretação teórica de um conjunto de dados (HAIR et al. 2009). Entre essas técnicas estão a análise por componentes principais e os métodos de agrupamento, como o de otimização de Tocher e o UPGMA (Unweighted Pair-Group Method using Arithmetic Avarages) (OLIVEIRA et al. 2019a). Esses métodos são importantes no melhoramento genético vegetal, pois permitem a estimativa da distância entre genótipos. Desta forma, evitam a conservação de duplicatas em bancos de germoplasma e auxilia na escolha de genitores para cruzamentos futuros visando maior ganho por heterose (VIDAL et al. 2018).

Objetivou-se com este trabalho, indicar a contribuição relativa dos caracteres avaliados para a dissimilaridade genética e avaliar a divergência genética entre genótipos de tipos especiais de arroz por dois métodos diferentes de agrupamento.

\section{MATERIAL E MÉTODOS}

O experimento foi realizado na área experimental do Departamento de Fitotecnia do Instituto de Agronomia da Universidade Federal Rural do Rio de Janeiro (UFRRJ), município de Seropédica, RJ, situado a $22^{\circ} 45^{\prime} \mathrm{S}, 43^{\circ} 41^{\prime} \mathrm{W}$ e 35 metros de altitude, no período de outubro de 2012 a março de 2013 . O solo foi classificado como Planossolo Háplico - Série Ecologia (EMBRAPA 2006), distrófico, textura arenosa. Durante o período de cultivo foi registrado temperatura média diária de $25,57^{\circ} \mathrm{C}$, umidade relativa média de $81,24 \%$, precipitação pluvial média mensal de $172,55 \mathrm{~mm}$ e $1.446,33 \mathrm{KJ} \cdot \mathrm{m}^{-2}$ de radiação solar, de acordo com os dados meteorológicos da Estação Ecologia Agrícola (83741), localizada no município de Seropédica, RJ.

Antes da instalação do experimento foram coletadas amostras de solo da área para a realização da análise química, com os seguintes resultados: $\mathrm{pH}=5,6 ; \mathrm{P}=87 \mathrm{mg} \mathrm{dm}^{-3} ; \mathrm{K}=23 \mathrm{mg} \mathrm{dm}^{-3} ; \mathrm{Ca}=4,0 \mathrm{cmol}_{\mathrm{c}}$ $\mathrm{dm}^{-3} ; \mathrm{Mg}=2,0 \mathrm{cmol}_{\mathrm{c}} \mathrm{dm}^{-3} ; \mathrm{Al}=0,0 \mathrm{cmol}_{\mathrm{c}} \mathrm{dm}^{-3}$.

$O$ delineamento experimental foi o de blocos ao acaso com cinco repetições. $A$ área das parcelas foi de $16 \mathrm{~m}^{2}$, constituída de oito fileiras de $4 \mathrm{~m}$ de comprimento e espaçamento de $0,5 \mathrm{~m}$ entre as mesmas. A área útil de cada parcela constou das quatro fileiras centrais, excluindo-se $1 \mathrm{~m}$ de cada extremidade dessas fileiras, correspondendo a $4 \mathrm{~m}^{2}$ de área. Os tratamentos constaram da cultivar de terras altas Caiapó (arroz branco) e das cultivares especiais IAC 300 (arbório), IAC 400 (glutinoso), IAC 500 (aromático) e Vermelho Pequeno, que é uma linhagem de grãos vermelhos selecionada na UFRRJ.

O sistema de produção utilizado foi o de sequeiro, cultivado em solo de várzea, sem irrigação (com irrigação suplementar por aspersão). A semeadura em linha foi realizada após a abertura dos sulcos e marcação dos blocos e parcelas, com uma densidade de 70 sementes por metro, ajustada de acordo com os resultados dos testes de germinação e peso das sementes de cada cultivar, utilizando-se espaçamento de $0,50 \mathrm{~m}$ entre as fileiras. Foi realizada uma adubação por ocasião da semeadura com a aplicação de 30 $\mathrm{kg} \mathrm{ha}^{-1}$ de $\mathrm{N}$ e $30 \mathrm{~kg} \mathrm{ha}^{-1}$ de $\mathrm{K}_{2} \mathrm{O}$, mais duas aplicações em cobertura durante o ciclo da cultura, com os mesmos nutrientes e dosagens da aplicação anterior: uma aos 30 dias após a semeadura e outra na fase de elongação da panícula (R2, emborrachamento), uma semana antes da floração. As fontes de nitrogênio e de potássio utilizadas foram o sulfato de amônio e o cloreto de potássio, respectivamente. $\mathrm{O}$ controle de plantas espontâneas foi realizado com duas capinas manuais durante a fase vegetativa das plantas.

Foram avaliados os seguintes componentes da produção e características agronômicas: Número de panículas viáveis por $\mathrm{m}^{2}$ (NPVM): foi realizada a contagem do número de panículas viáveis por $\mathrm{m}^{2}$ de cada parcela, considerando aquelas com pelo menos uma espigueta cheia; Número de espiguetas por panículas (NEP): foram selecionadas ao acaso dez panículas viáveis de cada parcela e efetuada a contagem das espiguetas de cada uma delas, obtendo-se a média de espiguetas por panícula; Porcentagem de espiguetas férteis por panícula (EFP): nas dez panículas avaliadas, foi obtida a relação entre o número de espiguetas férteis, com grãos cheios, e o número total de espiguetas por panícula; Peso de 100 espiguetas (P100): definido pela média de cinco amostras de 100 espiguetas férteis de cada parcela dos tratamentos, 
sendo o teor de água das espiguetas ajustado para 13\%; Índice de colheita (IC): relação da massa de matéria seca das espiguetas férteis e de massa seca total da parte aérea de dez perfilhos com panículas, escolhidos ao acaso em cada parcela; Porte da planta (PP): avaliado tomando-se dez plantas ao acaso de cada parcela e medindo a altura da superfície do solo até a extremidade da panícula mais alta; Floração Média (FM): número de dias ocorridos da emergência média das plântulas até o florescimento de $50 \%$ das panículas de cada parcela; Ciclo da cultura (CC): número de dias transcorridos da semeadura ao ponto de colheita, ou seja, quando $80 \%$ das panículas de cada parcela apresentavam $2 / 3$ das espiguetas maduras; Produtividade (PROD): obtida pela produção de grãos com casca a 13\% de umidade e expressa em kg ha ${ }^{-1}$.

Foi aplicada a análise dos componentes principais, a fim de saber quais das variáveis avaliadas apresentam maior variância (CRUZ et al. 2014). Para analisar a divergência genética entre os genótipos, foi realizada uma análise de agrupamento aplicada às médias das repetições para cada variável. A medida de dissimilaridade adotada foi a distância euclidiana, utilizando as médias dos valores das parcelas para cada variável. Os tratamentos foram então agrupados por dois métodos diferentes: o método de otimização de Tocher e o método hierárquico UPGMA (Unweighted Pair-Group Method using Arithmetic Avarages). A validação do agrupamento pelo método UPGMA foi determinada pelo coeficiente de correlação cofenética. As análises estatísticas foram realizadas por meio do programa $R$ versão 3.1.2. (R DEVELOPMENT CORE TEAM 2006).

\section{RESULTADOS E DISCUSSÃO}

As variáveis de maiores pesos nos primeiros autovetores são consideradas de maior importância no estudo da divergência genética. Essas características devem ser priorizadas na escolha de genitores em programas de melhoramento (MELO et al. 2019). Normalmente o valor mínimo de $80 \%$ indica que o autovetor explica uma fração considerável da variação disponível (CRUZ et al. 2014). Desta forma, observando os resultados da análise de componentes principais (Tabela 1), verifica-se que o componente principal I (PROD) foi responsável por quase toda a variância $(98,86 \%)$.

As variáveis que apresentarem maiores coeficientes a partir do último componente principal, em valor absoluto, são passíveis de descarte (PAIVA et al. 2010, COIMBRA et al. 2010). Isso porque estão correlacionadas com outras características. No presente estudo, fazendo análise dos autovetores, verificase que essas características foram o NPVM $(-0,949)$, PP $(-0,819)$, EFP $(0,733)$ e NEP $(0,551)$ (Tabela 1). Em DALCHIAVON et al. (2012), a massa de mil grãos foi o componente da produção que menos contribuiu para a produtividade de grãos.

Tabela 1. Autovetores, desvio padrão, variâncias percentuais (VCP\%) e variância acumulada (VCPac) dos componentes principais.

Table 1. Eigenvectors, standard deviation, percentage variances (\%) and cumulative variances of the main components.

\begin{tabular}{llllll}
\hline & CPI & CPII & CPIII & \multicolumn{1}{l}{ CPIV } & \multicolumn{1}{c}{ CPV } \\
\hline PROD & $-0,99943$ & 0,01793 & 0,01712 & $-0,00925$ & $-0,01335$ \\
NPVM & $-0,02374$ & $-0,94929$ & $-0,23550$ & $-0,10172$ & 0,09259 \\
NEP & $-0,02108$ & 0,10802 & $-0,08236$ & 0,51800 & 0,55135 \\
EFP & $-0,00228$ & $-0,10360$ & $-0,04386$ & 0,73387 & $-0,31003$ \\
P100 & 0,00041 & 0,00678 & 0,00320 & $-0,03724$ & 0,04791 \\
FM & $-0,00571$ & 0,03118 & $-0,13128$ & 0,05040 & 0,03771 \\
PP & $-0,00760$ & 0,13358 & $-0,81972$ & 0,11831 & $-0,07032$ \\
IC & $-0,00104$ & 0,02017 & 0,08109 & $-0,06426$ & 0,22516 \\
CC & $-0,00054$ & 0,03198 & 0,01663 & $-0,02904$ & $-0,52997$ \\
DesvPad & 1416,060 & 49,0816 & 17,2106 & 9,69735 & $4,799 \mathrm{e}-15$ \\
VCP\% & 99,86 & 0,12 & 0,02 & 0,01 & $<0,01$ \\
VCPac & 99,86 & 99,98 & 99,99 & 1,00 & 1,00 \\
\hline
\end{tabular}

PROD $=$ produtividade; NPVM $=n^{\circ}$ panículas viáveis por $\mathrm{m}^{2} ; \mathrm{NEP}=\mathrm{n}^{\circ}$ espiguetas por panícula; EFP $=$ espiguetas férteis por panícula; $\mathrm{P} 100$ = peso de cem espiguetas; FM = floração média; $\mathrm{PP}=$ porte da planta; IC = índice de colheita; $\mathrm{CC}=$ ciclo cultural; DesvPad = desvio padrão; VCP\% = variâncias percentuais; VCPaC = variância acumulada.

Na Figura 1 são apresentadas as dispersões gráficas dos cinco genótipos (1- Caiapó; 2- Vermelho Pequeno; 3- IAC 300; 4- IAC 400; 5- IAC 500) em relação aos eixos dos componentes principais, nas duas primeiras variáveis canônicas, estabelecidas com base em nove características. Ao analisar o gráfico observa-se que não foi possível, pela proximidade, a separação de grupos de genótipos. O estudo da 
dispersão gráfica deve ser realizado quando for possível resumir em poucas variáveis $80 \%$ da variação total disponível (CRUZ et al. 2014). Com isso, a não formação de grupos se deve ao fato da característica PROD reter a maior parte da variação disponível, o que pode ser justificado pela menor variabilidade genética entre os genótipos avaliados (Tabela 1).

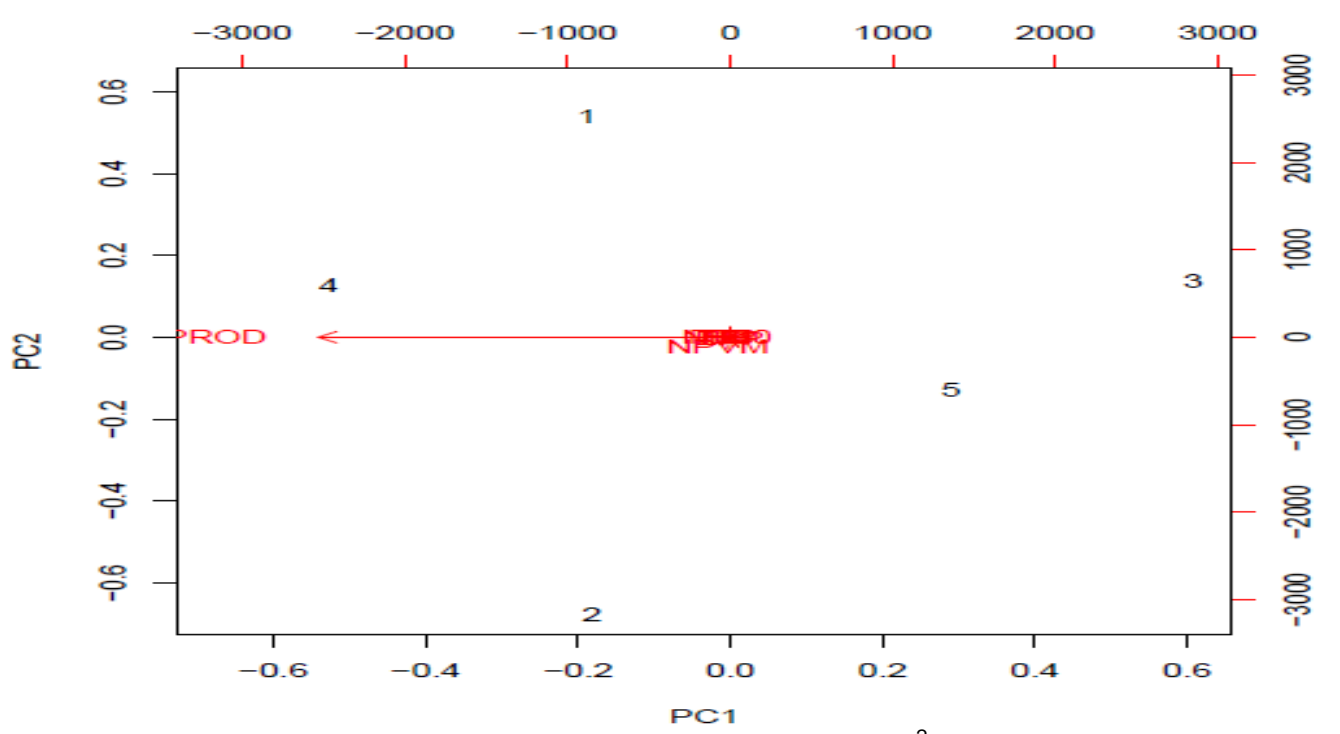

PROD = produtividade; NPVM $=n^{\circ}$ panículas viáveis por $m^{2} ; N E P=n^{\circ}$ espiguetas por panícula; EFP = espiguetas férteis por panícula; $\mathrm{P} 100$ = peso de cem espiguetas; FM = floração média; $P P=$ porte da planta; IC = índice de colheita; $C C=$ ciclo cultural. 1 = Caiapó; 2 = Vermelho Pequeno; 3 = IAC 300; 4 = IAC 400; 5 = IAC 500.

Figura 1. Gráfico dos componentes principais das características avaliadas.

Figure 1. Graph of the main components of the evaluated characteristics.

O método de agrupamento de Tocher dividiu os genótipos em três grupos heteróticos (Tabela 2). Onde no grupo I tem-se a cultivar Caiapó e a linhagem Vermelho Pequeno; no grupo II, as cultivares IAC 300 e IAC 500; e no grupo III, somente a cultivar IAC 400. Genótipos encontrados em grupos distintos são considerados divergentes, enquanto os que são encontrados em mesmo grupo apresentam alta similaridade (ALJUMAILI et al. 2018). A linhagem Vermelho Pequeno que apresenta arquitetura de planta com folha bandeira ereta (MENEZES et al. 2011), porém com porte relativamente alto, folhas longas e decumbentes, com possibilidade de autossombreamento em condições de cultivo comercial, demonstrou bom desempenho nas condições de cultivo em sequeiro, como em ROCHA et al. (2020). A linhagem Vermelho Pequeno e a cultivar Caiapó, recomendada para o cultivo em sequeiro, mostraram-se ser as mais próximas geneticamente.

Tabela 2. Agrupamento pelo método de Tocher utilizando a distância euclidiana como medida de distância genética.

Table 2. Grouping by the Tocher method using the Euclidean distance as a measure of genetic distance.

\begin{tabular}{ll}
\hline Grupo & Genótipo \\
\hline I & Caiapó; Vermelho Pequeno \\
II & IAC 300; IAC400 \\
III & IAC500
\end{tabular}

O agrupamento feito pelo método UPGMA apresentou uma alta correlação cofenética com a distância euclidiana $(r=0,8589)$. Diferentemente do resultado obtido com o método anterior, foram formados dois grupos (Figura 2), onde as cultivares IAC 300 e IAC 500, foram agrupadas em um grupo heterótico distinto das demais. Analisando os resultados dos dois métodos, fica mais claro a proximidade da linhagem Vermelho Pequeno com a cultivar Caiapó (Tabela 2; Figura 2). Nota-se que pelo método UPGMA a cultivar IAC 400 foi agrupada juntamente com a cultivar Caiapó e a linhagem Vermelho Pequeno (Figura 2). Porém pelo método de Tocher a cultivar IAC 400 não foi agrupada com nenhuma outra (Tabela 2).

O agrupamento de Tocher detectou três grupos demostrando coerência em relação ao UPGMA, onde foram detectados dois grupos. Concordância entre os dois métodos também foi observada em BOHRY et al. (2019). Porém, as cultivares IAC 400 e IAC 500 na análise pelos dois métodos de otimização estiveram em 
grupos distintos. Isso demostra a importância do melhorista que ao avaliar a divergência genética utilize mais de um método de agrupamento (OLIVEIRA et al. 2019b).

A cultivar IAC 400 trata-se de arroz do tipo glutinoso, de grão curto e originário da China, localizada na Ásia Oriental. Enquanto que o arroz aromático (cultivar IAC 500), tipo basmati, possui grão longos e origem na Índia, localizada na Ásia Meridional. A divergência genética, não necessariamente reflete na origem geográfica, mas está relacionada aos genes que esses genótipos possuem (GONÇALVES et al. 2014). Essas informações sobre a distância genética são importantes em programas de melhoramento, pois auxiliam na escolha de genitores para o desenvolvimento de novos híbridos. Isso porque apresentam maior variabilidade para as características a serem melhoradas (AZEVEDO et al. 2013).

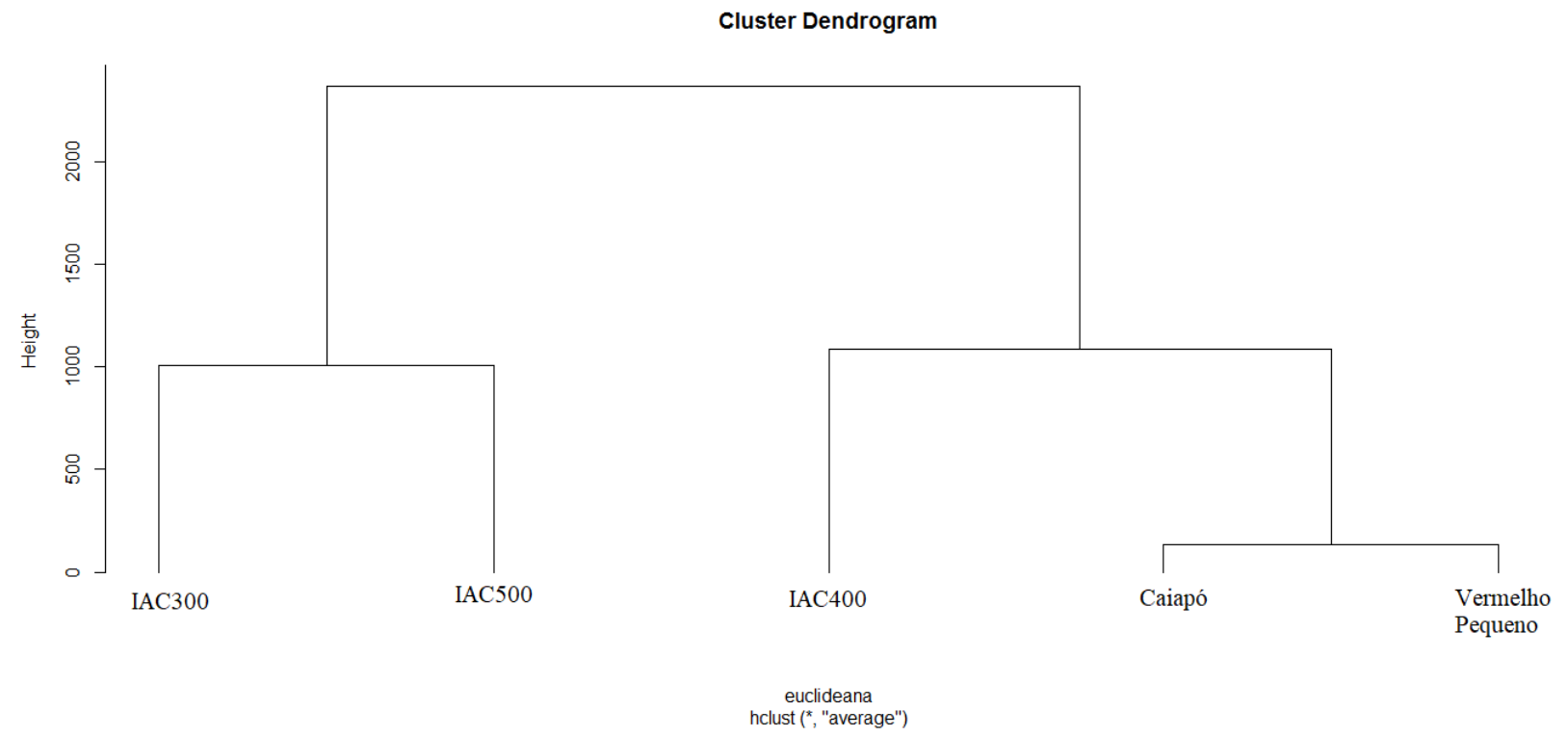

Figura 2. Dendrograma hierárquico obtido pelo método de agrupamento UPGMA a partir da distância euclidiana entre os tratamentos.

Figure 2. Hierarchical dendrogram obtained by the UPGMA grouping method from the Euclidean distance between the treatments.

\section{CONCLUSÃO}

A produtividade é a característica responsável por mais de $90 \%$ da divergência genética.

Os genótipos Caiapó e Vermelho Pequeno pertencem ao mesmo grupo heterótico pelos dois métodos de agrupamento: de Tocher e UPGMA.

As cultivares IAC 400 (glutinoso) e IAC 500 (aromático) pertencem a grupos heteróticos distintos com base no agrupamento de Tocher e UPGMA.

\section{REFERÊNCIAS}

ALJUMAILI SJ et al. 2018. Genetic diversity of aromatic rice germplasm revealed by SSR markers. BioMed Research International 2018: ID 7658032.

ANGGRAINI T et al. 2015. Antioxidant activities of some red, black and white rice cultivar from West Sumatra, Indonesia. Pakistan Journal of Nutrition 14: 112-117.

AZEVEDO AM et al. 2013. Seleção de genótipos de alface para cultivo protegido: divergência genética e importância de caracteres. Horticultura Brasileira 31: 260-265.

BOHRY D et al. 2019. Characterization and genetic divergence of araçá-boi based on physicochemical and colorimetric traits of fruits. Revista de Ciências Agrárias 62: rca.2019.3004.

COIMBRA RR et al. 2010. Caracterização e divergência genética de populações de milho resgatadas do Sudeste de Minas Gerais. Revista Ciência Agronômica 41: 159-166.

CRUZ CD et al. 2014. Modelos biométricos aplicados ao melhoramento genético. Viçosa: UFV. 668p.

DALCHIAVON FC et al. 2012. Correlação linear entre componentes da produção e produtividade do arroz de terras altas em sistema de plantio direto. Semina: Ciências Agrárias 33: 1629-1642.

EMBRAPA. 2006. Empresa Brasileira de Pesquisa Agropecuária. Sistema Brasileiro de Classificação de Solos. Rio de Janeiro: Embrapa Solos. 306p.

GONÇALVES DL et al. 2014. Divergência genética de acessos tradicionais de feijoeiros através de características da semente. Bioscience Journal 30: 1671-1681. 
HALLAUER AR \& MIRANDA JB. 1988. Germplasm. In: HALLAUER AR \& MIRANDA JB. (2.ed.). Quantitative genetics in maize breeding. Ames: lowa State University Press. p.375-396.

HAIR JF et al. 2009. Análise multivariada de dados. 6.ed. Porto Alegre: Editora Bookman. 688p.

MELO AV et al. 2019. Divergência genética entre híbridos de milho em condições de deficiência hídrica. Revista de Agricultura Neotropical 6: 66-75.

MENEZES BRS et al. 2011. Caracterização morfoagronômica em arroz vermelho e arroz de sequeiro. Pesquisa Agropecuária Tropical 41: 490-499.

MENEZES BRS et al. 2013. Avaliação da germinação e dormência de sementes de arroz vermelho e branco. Revista de Ciências Agroveterinárias 12: 129-140.

NASS LL et al. 1992. Utilization of genetic resources for maize and syubean breeding in Brazil. Brazilian Journal of Genetics 16: 983-988.

OLIVEIRA ACR et al. 2019a. Genetic divergence between pepper accessions based on quantitative fruit traits. Científica 47: 83-90.

OLIVEIRA CS de et al. 2019b. Características de plântulas: dissimilaridade genética entre acessos de pimenta. Ciência, Tecnologia \& Ambiente 9: e09114.

PAIVA ALC et al. 2010. Análise de componentes principais em características de produção de aves de postura. Revista Brasileira de Zootecnia 39: 285-288.

R DEVELOPMENT CORE TEAM. 2006. A language and environment for statistical computing. Vienna: R Foundation for Statistical Computing. Disponível em http://www.r-project.org/. Acesso em: 30 jun. 2013.

ROCHA G et al. 2020. Características morfoagronômicas na colheita principal e na soca e análise de trilha em tipos especiais de arroz. Cultura Agronômica 29: 38-49.

VEIGA RFA et al. 2012. Bancos de germoplasma: importância e organização. In: COSTA AM et al. (Ed.). Conservação de recursos genéticos no Brasil. Brasília: Embrapa. p.104-105.

VIDAL AKF et al. 2018. Estimative of genetic diversity in germ-plasm of elephant grass using the Gower algorithm. Genetics and Molecular Research 17: gmr16039934. 